\title{
Pró-calcitonina e proteína $C$ reativa em processos infecciosos graves
}

\author{
Procalcitonin and C-reactive protein in septic patients
}

Adagmar Andriolo'; Roberta Pasianotto Costa²; Neil Ferreira Novo ${ }^{3}$

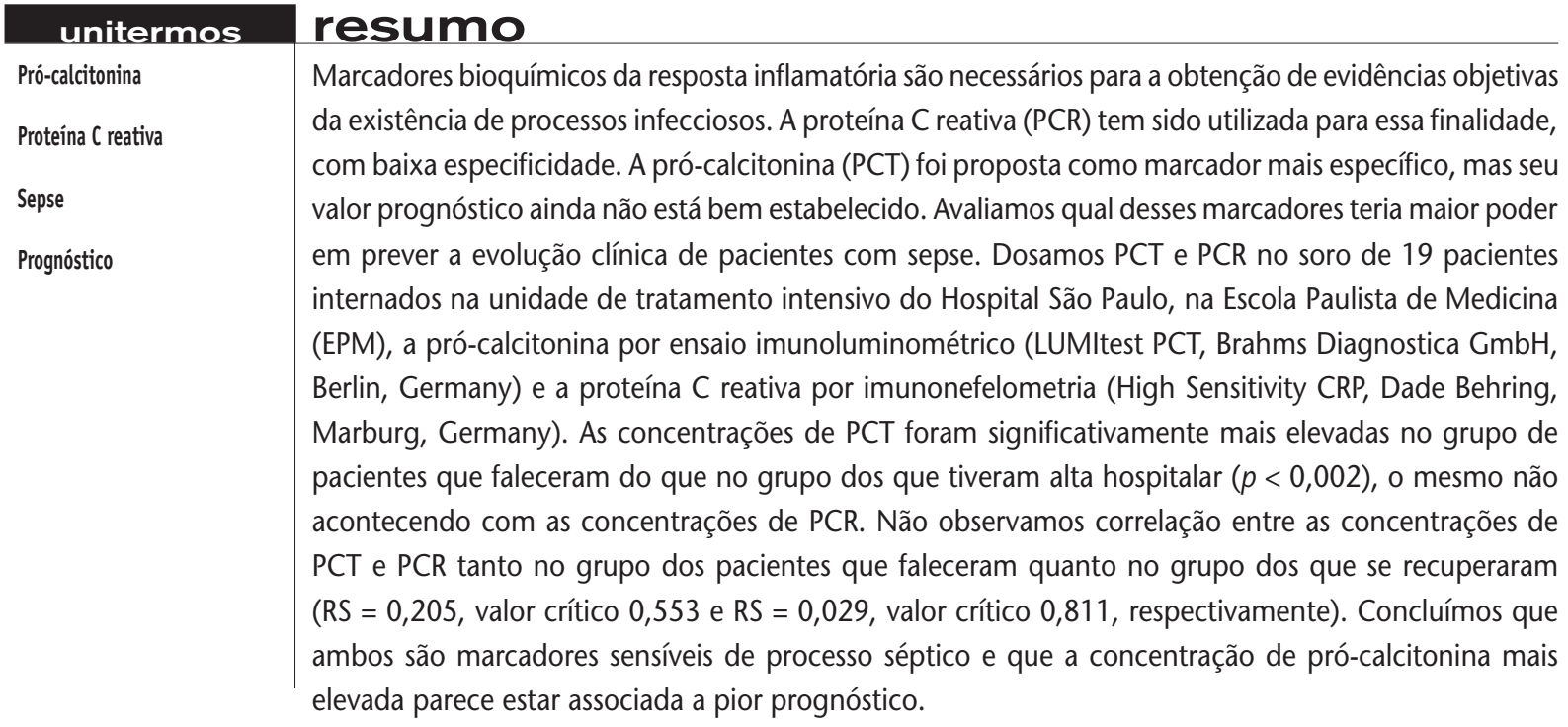

abstract

Biochemical markers for septic processes are necessary in order to obtain objective evidence of sepsis. The $C$-reactive protein (CRP) has been used to that, despite its low specificity. The procalcitonin (PCT) was proposed as a more specific marker, but its predictive value is not yet well established. We evaluated which one of that markers could anticipate the clinical output of septic patients. Determination of PCT/CRP was performed in 19 sera from patients from ITU of Hospital São Paulo/EPM. Procalcitonin was measured by immunoluminometric assay (LUMItest PCT, Brahms Diagnostica GmB, Berlin, Germany) and C-reactive protein by immunonephelometric assay (N High Sensitivity CRP, Dade Behring, Marburg, Germany). The PCT concentrations are significantly higher in non-survivors than in survivors group $(\mathrm{p}<0.002)$, what did not occur with CRP. We did not observe significant correlation between procalcitonin and C-reactive protein concentrations as in non-survival as survival group $(S R=0.205$, critic value 0.533 and $S R=0.029$, critic value 0.811 , respectively). We concluded that both markers are sensitive for septic process and that higher procalcitonin concentration could be related to a worse prognostic. 


\section{Introdução}

A pró-calcitonina (PCT) é uma proteína de 116 aminoácidos com seqüência idêntica à do proto-hormônio calcitonina, produzida pelas células $C$ da glândula tireóide. Em condições normais, essa proteína está presente em concentrações muito baixas na circulação, permanecendo no interior das células como principal peptídeo precursor da calcitonina(3).

Nas infecções bacterianas limitadas a um órgão, em geral não se observa elevação significativa na concentração de PCT, mas nos processos bacterianos graves, com sepse, níveis extremamente elevados de pró-calcitonina intacta podem ser encontrados na circulação. Trabalhos recentes têm sugerido que, nesses casos, a produção é extratireoidiana, sendo que leucócitos ${ }^{(15,16)}$, macrófagos, células monocíticas de vários órgãos, como fígado, pulmão e intestino(1, 2, 14), e células neuroendócrinas têm sido responsabilizados pela síntese de PCT em resposta à infecção bacteriana.

Em condições fisiológicas, apenas uma pequena quantidade de pró-calcitonina intacta está presente na circulação, sendo que a maior porção apenas é secretada após proteólise. Existem algumas evidências de que a proteólise é suprimida pela ação de citoquinas e endotoxinas, resultando na liberação da molécula intacta para a circulação ${ }^{(4,19)}$. Adicionalmente, está bem documentado que a transcrição do PCT-RNAm é substancialmente aumentada por estímulos inflamatórios ${ }^{(16)}$, resultando em aumento de síntese.

Por essas características, tem sido proposto que a PCT possa ser utilizada como um parâmetro para diagnóstico e monitoração da sepse, indicando a extensão da reação inflamatória sistêmica e, eventualmente, auxiliando no estabelecimento do prognóstico.

Vários estudos clínicos têm demonstrado a habilidade da PCT em detectar, precocemente, a sepse e em diferenciar processos infecciosos virais de bacterianos. Trabalhos experimentais têm demonstrado que a indução de síntese e a liberação ocorrem de forma bastante rápida, observando-se concentrações elevadas entre duas e seis horas após estímulo infeccioso, que tendem a se normalizar, também precocemente, quando da recuperação do paciente ${ }^{(6,11,12)}$. Pessoas sadias possuem concentrações de pró-calcitonina circulante em níveis inferiores a $0,1 \mathrm{ng} / \mathrm{ml}$, abaixo do limite de detecção dos métodos rotineiramente disponíveis. Concentrações acima de 0,5ng/ml indicam ou a existência de processo infeccioso agudo ou resposta inflamatória sistêmica, e concentrações elevadas ou persistentemente altas indicam pior prognóstico.
A PCT in vivo é estável, possuindo meia-vida de, aproximadamente, 20 a 24 horas ${ }^{(7,17)}$. A concentração in vitro se reduz cerca de $12 \%$ à temperatura ambiente e $6 \%$ se mantida a $4^{\circ} \mathrm{C}$, em 24 horas ${ }^{(5,13)}$. A coleta de sangue pode ser realizada seguindo-se os procedimentos habituais do laboratório clínico, sem necessidade de condições especiais. Caso a dosagem não seja realizada no dia da coleta, o soro deve ser mantido congelado.

A proteína $C$ reativa $(P C R)$ é uma das proteínas de fase aguda de comportamento positivo, ou seja, a concentração sérica se eleva marcadamente logo após a ocorrência de uma agressão ao organismo. Consiste em um complexo formado por cinco subunidades polipeptídicas sintetizadas pelo fígado, ligadas não covalentemente, com peso molecular aproximado de $115 \mathrm{Kda}$ a $140 \mathrm{Kda}$.

Classicamente, a PCR tem sido utilizada como marcador precoce e sensível da resposta aos processos infecciosos ou inflamatórios, elevando-se cerca de 20 a 2 mil vezes em relação aos níveis basais, de 24 a 28 horas após o estímulo ${ }^{(8,9)}$ e, para esta finalidade, considera-se limite de referência a concentração sérica de até $0,50 \mathrm{mg} / \mathrm{dl}^{(10)}$.

\section{Objetivos}

Avaliar as concentrações de pró-calcitonina e de proteína $C$ reativa no soro de pacientes com processos infecciosos graves, com sepse, correlacionando-as com a evolução clínica.

\section{Material e método}

Foram realizadas dosagens concomitantes de pró-calcitonina e proteína $C$ reativa no soro de 19 pacientes internados na unidade de tratamento intensivo do Hospital São Paulo, na Escola Paulista de Medicina (EPM), sendo cinco mulheres e 14 homens, com idades entre 25 e 80 anos (média 54,2 anos, desvio-padrão 17,4 anos e mediana 60 anos). Os dados epidemiológicos estão apresentados na Tabela 1.

A pró-calcitonina foi dosada por ensaio imunoluminométrico (LUMItest PCT, Brahms Diagnostica GmbH, Berlin, Germany) e a proteína $C$ reativa foi dosada por método imunonefelométrico (High Sensitivity CRP, Dade Behring Marburg Germany).

\section{Tratamento estatístico}

Para a análise dos resultados das dosagens de PCT e PCR, aplicou-se o teste de Mann-Whitney para com- 
paração do grupo dos pacientes que evoluíram para óbito com o grupo dos que se recuperaram. Utilizou-se o coeficiente de correlação de Spearman para avaliação da relação entre os valores de PCT e PCR em cada um dos grupos estudados. Fixou-se em 0,05 ou $5 \%$ o limite de significância.

\section{Resultados}

Os pacientes foram classificados em dois grupos, segundo a evolução clínica. Um grupo foi constituído pelos 13 pacientes que faleceram no período da internação no qual a amostra foi coletada e um segundo grupo foi constituído pelos seis pacientes que se recuperaram do processo infeccioso, tendo alta hospitalar.

Os resultados das dosagens de $\mathrm{PCT}$ no grupo dos pacientes que faleceram variaram de $0,39 \mathrm{ng} / \mathrm{ml}$ a $124,56 \mathrm{ng} / \mathrm{ml}$, e os da PCR ficaram entre $1,17 \mathrm{mg} / \mathrm{dl}$ e $28 \mathrm{mg} / \mathrm{dl}$. No grupo dos pacientes que evoluíram para a cura, os resultados da PCT foram de $0,2 \mathrm{ng} / \mathrm{ml}$ a $1,82 \mathrm{ng} / \mathrm{ml}$, e os da PCR se mantiveram entre $3,47 \mathrm{mg} / \mathrm{dl}$ e $15,7 \mathrm{mg} / \mathrm{dl}$. Os resultados individuais dessas dosagens estão descritos nas Tabelas 2 e 3 , respectivamente.

\section{Discussão}

O diagnóstico precoce e o tratamento adequado dos quadros sépticos contribuem para a redução da morbidade e da mortalidade, habitualmente elevadas nestas graves situações clínicas. A utilização de marcadores bioquímicos com elevadas sensibilidade e especificidade é necessária para que o laboratório clínico possa fornecer, rapidamente, evidências objetivas da existência ou não de processos infecciosos.

A proteína $\mathrm{C}$ reativa, ainda que altamente sensível para essa finalidade, carece de especificidade, apresentando-se elevada em situações outras que não-infecciosas, como traumas cirúrgicos, doenças inflamatórias e auto-imunes.

A pró-calcitonina foi, recentemente, proposta como um marcador mais específico da resposta inflamatória à infecção, elevando-se marcadamente nos casos de bacteremia e sepse, e não se alterando com igual intensidade

Identificação, sexo, idade, diagnóstico e antecedentes mórbidos dos pacientes incluídos

Tabela 1 no estudo

\begin{tabular}{|c|c|c|c|c|}
\hline Identificação & Sexo & Idade (anos) & Diagnóstico & Antecedentes mórbidos \\
\hline SSR & F & 30 & Sepse & Puerpério, dor abdominal, $\mathrm{BCP}$ \\
\hline ATA & $\mathrm{F}$ & 25 & Sepse & Lúpus eritematoso, vasculite, hemoptise \\
\hline $\mathrm{ABP}$ & $\mathrm{F}$ & 66 & Sepse & $\begin{array}{c}\text { Neoplasia de pâncreas, ferida } \\
\text { cirúrgica infectada }\end{array}$ \\
\hline MROL & $\mathrm{F}$ & 70 & Sepse & $\mathrm{BCP}$ \\
\hline ZS & $\mathrm{F}$ & 80 & Sepse & $\mathrm{BCP}$ \\
\hline SPEF & M & 65 & Sepse & Etilismo, hepatopatia, ascite \\
\hline MSM & M & 67 & Sepse & $\mathrm{BCP}$ \\
\hline NMS & M & 57 & Sepse & $\mathrm{BCP}$, tabagismo, etilismo \\
\hline $\mathrm{JR}$ & M & 70 & Sepse & DPOC, ferida cirúrgica infectada \\
\hline VPP & M & 40 & Meningite & Aids, TCE \\
\hline LB & M & 78 & Sepse & $\mathrm{BCP}$ \\
\hline RFL & M & 32 & Sepse & Aids, BCP \\
\hline SOB & M & 51 & Sepse & AVC, ITU \\
\hline AVG & M & 32 & Sepse & Politraumatismo, BCP \\
\hline JDPB & M & 46 & Sepse & Craniotomia, BCP \\
\hline JS & M & 34 & Sepse & $\mathrm{BCP}$ \\
\hline $\mathrm{COA}$ & M & 63 & Sepse & IRC, pneumotórax pós-cirurgia de tumor renal \\
\hline FQO & M & 64 & Sepse & $\mathrm{BCP}$ \\
\hline RBMT & M & 60 & Sepse & Pneumomediastino \\
\hline
\end{tabular}

$F=$ feminino; $M=$ masculino; $B C P=$ broncopneumonia; $D P O C=$ doença pulmonar obstrutiva crônica; Aids = síndrome de imunodeficiência adquirida; $T C E$ = trauma craniencefálico; $A V C=$ acidente vascular cerebral; ITU = infecção do trato urinário; IRC = insuficiência renal crônica. 


\begin{tabular}{lcc} 
Tabela 2 & $\begin{array}{l}\text { Resultados das dosagens de pró-calcitonina e proteína C reativa no soro dos pacientes } \\
\text { que faleceram }\end{array}$ & \\
\hline Identificação & Pró-calcitonina $(\mathrm{ng} / \mathrm{ml})$ & Proteína C reativa $(\mathrm{mg} / \mathrm{dl})$ \\
\hline ATA & 0,39 & 1,17 \\
ABP & 2,11 & 18,7 \\
MROL & 1,98 & 19 \\
ZS & 13,93 & 10,2 \\
SPEF & 3,45 & 2,51 \\
MSM & 1,93 & 16,6 \\
NMS & 1,86 & 17 \\
JR & 1,63 & 10,7 \\
VPP & 124,56 & 18 \\
LB & 1,45 & 3,44 \\
RFL & 0,51 & 28 \\
COA & 6,39 & 18 \\
FQ0 & 6,34 & 26,6 \\
& & 14,61 \\
Média & 12,81 & 17 \\
Mediana & 1,98 & 8,56 \\
Desvio-padrão & 33,78 & \\
\hline
\end{tabular}

\begin{tabular}{|c|c|c|}
\hline abela 3 & \multicolumn{2}{|c|}{$\begin{array}{l}\text { Resultados das dosagens de pró-calcitonina e proteina C reativa no soro dos pacientes que } \\
\text { evoluiram para cura do processo infeccioso }\end{array}$} \\
\hline Identificação & Pró-calcitonina (ng/ml) & Proteina C reativa (mg/dl) \\
\hline SSR & 1,82 & 4,55 \\
\hline SOB & 0,2 & 14,5 \\
\hline AVG & 0,37 & 7,52 \\
\hline JDPB & 0,36 & 3,47 \\
\hline JS & 0,42 & 15,7 \\
\hline RBMT & 0,38 & 12,2 \\
\hline Média & 0,59 & 9,66 \\
\hline Mediana & 0,38 & 9,86 \\
\hline Desvio-padrão & 0,61 & 5,20 \\
\hline \multicolumn{3}{|c|}{$\begin{array}{l}\text { Teste de Mann-Whitney } \\
\text { (óbito } x \text { recuperação) }\end{array}$} \\
\hline & РСТ & PCR \\
\hline & $\begin{array}{l}\text { Valor calculado }=5 \\
\quad(p<0,002)\end{array}$ & $\begin{array}{l}\text { Valor calculado }=24 \\
\text { não-significativo }\end{array}$ \\
\hline & \multicolumn{2}{|c|}{$\begin{array}{l}\text { Coeficiente de correlação de Spearman } \\
\text { (PCT } \times \text { PCR) }\end{array}$} \\
\hline & Óbito & Recuperação \\
\hline & $\mathrm{RS}=0,205$ & $\mathrm{RS}=0,029$ \\
\hline & $\mathrm{R}$ crítico $=0,553$ & $\mathrm{R}$ crítico $=0,811$ \\
\hline
\end{tabular}


nas infecções virais, infecções bacterianas localizadas e nos processos não-infecciosos.

O valor prognóstico da PCT em relação à sobrevida dos pacientes com sepse, quando comparado com a PCR, ainda não está perfeitamente estabelecido. Neste trabalho, procuramos avaliar qual dos dois marcadores teria maior poder em prever a evolução clínica de pacientes com essa condição clínica.

A aplicação do teste estatístico de Mann-Whitney permitiu concluir que as concentrações de PCT foram significativamente mais elevadas no grupo dos pacientes que evoluíram mal, chegando a óbito, do que no grupo dos pacientes que evoluíram para alta hospitalar $(p<0,002)$, com cura do processo infeccioso. O mesmo não aconteceu para as concentrações de PCR, que não se mostraram significativamente diferentes nos dois grupos.

O cálculo do coeficiente de Spearman mostrou não haver correlação significativa entre as concentrações de PCT e PCR, tanto no grupo dos pacientes que faleceram quanto no grupo dos pacientes que se recuperaram do processo infeccioso ( $R S=0,205$, valor crítico 0,553 e RS $=0,029$, valor crítico 0,811 , respectivamente).

\section{Conclusões}

Os dados obtidos permitem concluir que ambas, prócalcitonina e proteína $C$ reativa, são marcadores sensíveis de processo séptico, sendo que a concentração de pró-calcitonina mais elevada parece estar associada a pior prognóstico. Estudos futuros, com casuística maior e mais bem definida em termos de qualificação do estado séptico, serão estimulados pelas evidências sugeridas neste trabalho.

\section{Agradecimentos}

Os autores agradecem a Cyntia Yanikian pela assessoria técnica, à Brahms Diagnostica, Berlin, Germany, à Fanem Ltda. e ao Fleury - Centro de Medicina Diagnóstica pelo suporte operacional, indispensáveis para a realização deste trabalho.

\section{Referências}

I. BECKER, K. L. et al. Hyperprocalcitoninemia in inhalation burn injury: a response of the pulmonary neuroendocrine cell? Anat Rec, n. 236, p. 136-8, 1993.

2. BECKER, K. L.; GAZDAR, A. F. The pathophysiology of pulmonary calcitonin. The endocrine lung in health and disease. Philadelphia: Ed.W. B. Saunders, 1984.

3. BECKER, K. L.; NYLEN, E. S.; SNIDER, R. H. La procalcitonine circule chez les sujets normaux. Annales Endocrinologie, suppl. I, p. 59, 1996.

4. BECKER, K. L.; NYLEN, E. S.; THOMPSON, K. Preferential hypersecretion of procalcitonin and its precursors in pneumonitis: a cytokine-induced phenomeno? Endotoxemia and Sepsis Congress, Philadelphia, 1995. Abstract.

5. BRUNKHORST, F. M.; HEINZ, U.; FORYCKI, Z. F. Kinetics of procalcitonin in iatrogenic sepsis. Intens Care Med, n. 24, p. 888-92, 1998.

6. CLAEYS, R. et al. Plasma procalcitonin and C-reactive protein in acute septic shock: clinical and biological correlates. Crit Care Med, n. 30, p. 757-62, 2002.

7. DANDONA, P. et al. Procalcitonin increase after endotoxin injection in normal subjects. J Clin Endocrinol Metab, n. 79, p. 1605-8, 1994.

8. JOHNSON, A. M.; ROHLFS, E. M.; SILVERMAN, L. M. Proteins. In: Tietz textbook of clinical chemistry. 3. ed. Philadelphia:W. B. Saunders Company, 1999. p. 477-540.
9. KUSHENER, I.; RZEWNICKI, D. L. The acute phase response. General aspects. Baillière's Clinical Rheumatology, n. 8, p. 513-30, 1994.

10. MACY, E. M.; HAYES, T. E.; TRACY, R. P. Variability in the measurement of C-reactive protein in healthy subjects: implications for reference interval and epidemiological applications. Clin Chem, n. 43, p. 52-8, 1997.

I I. MEISNER, M. et al. Comparison of procalcitonin (PCT) and C-reactive protein (CRP) plasma concentrations at different Apache II scores during the course of sepsis and Mods. Anaesthesiology (Abstract), n. 87, p. 243, 1997.

12. MEISNER, M. et al. Procalcitonin (PCT) and CRP: comparison of plasma concentrations at different Sofa-scores during the course of sepsis and Mods. Shock (Abstract), n. 8, p. 47, 1997.

13. MEISNER, M. et al. Procalcitonin: influence of temperature, storage, anticoagulation and arterial or venous asservation of blood samples on procalcitonin concentrations. Eur J Clin Chem Clin Biochem, v. 35, n. 8, p. 597-601, 1997.

I4. NYLEN, E. S. et al. Pneumonitis-associated hyperprocalcitotinemia. Am J Med Sci, n. 312, p. 12-8, 1996.

15. OBERHOFFER, M. et al. Katacalcin and calcitonin immunereactivity in different types of leucocytes indicates intracellular procalcitonin content. J Crit Care, n. 14, p. 29-33, 1999.

16. OBERHOFFER, M. et al. Procalcitonin expression in human peripheral blood mononuclear cells and its modulation by 
lipopolysaccharides and sepsis related cytokines in vitro. J Lab Clin Med, n. I34, p. 49-55, 1999.

17. PETITJEAN, S. et al. Induction de la procalcitonine circulante après administration intraveneuse d'endotoxine chez I'homme. Act Pharm Biol Clin, p. 265-8, 1994.
18. SIEGEL, S.; CASTELLAN Jr., N. J. Nonparametric statistics. 2. ed. New York: McGraw-Hill Int, 1988. p. 399.

19. WHANG, K. T. et al. Serum calcitonin precursors in sepsis and systemic inflammation. J Clin Endocrinol Metab, n. 83, p. 3296-30I, 1998. 